\title{
Impact of chamber wall loss of gaseous organic compounds on secondary organic aerosol formation: explicit modeling of SOA formation from alkane and alkene oxidation
}

\author{
Y. S. La ${ }^{1}$, M. Camredon ${ }^{1}$, P. J. Ziemann ${ }^{2}$, R. Valorso ${ }^{1}$, A. Matsunaga ${ }^{3}$, V. Lannuque ${ }^{1}$, J. Lee-Taylor ${ }^{2,4}$, A. Hodzic ${ }^{4}$, \\ S. Madronich ${ }^{4}$, and B. Aumont ${ }^{1}$ \\ ${ }^{1}$ LISA, UMR CNRS 7583, Université Paris Est Créteil et Université Paris Diderot, 94010 Créteil CEDEX, France \\ ${ }^{2}$ Department of Chemistry and Biochemistry and Cooperative Institute for Research in Environmental Sciences (CIRES), \\ University of Colorado, Boulder, Colorado, USA \\ ${ }^{3}$ Air Pollution Research Center, University of California, Riverside, California, USA \\ ${ }^{4}$ National Center for Atmospheric Research, Boulder, Colorado, USA
}

Correspondence to: B. Aumont (bernard.aumont@lisa.u-pec.fr)

Received: 28 July 2015 - Published in Atmos. Chem. Phys. Discuss.: 3 September 2015

Revised: 24 December 2015 - Accepted: 21 January 2016 - Published: 8 February 2016

\begin{abstract}
Recent studies have shown that low volatility gasphase species can be lost onto the smog chamber wall surfaces. Although this loss of organic vapors to walls could be substantial during experiments, its effect on secondary organic aerosol (SOA) formation has not been well characterized and quantified yet. Here the potential impact of chamber walls on the loss of gaseous organic species and SOA formation has been explored using the Generator for Explicit Chemistry and Kinetics of the Organics in the Atmosphere (GECKO-A) modeling tool, which explicitly represents SOA formation and gas-wall partitioning. The model was compared with 41 smog chamber experiments of SOA formation under $\mathrm{OH}$ oxidation of alkane and alkene series (linear, cyclic and $\mathrm{C}_{12}$-branched alkanes and terminal, internal and 2methyl alkenes with 7 to 17 carbon atoms) under high $\mathrm{NO}_{x}$ conditions. Simulated trends match observed trends within and between homologous series. The loss of organic vapors to the chamber walls is found to affect SOA yields as well as the composition of the gas and the particle phases. Simulated distributions of the species in various phases suggest that nitrates, hydroxynitrates and carbonylesters could substantially be lost onto walls. The extent of this process depends on the rate of gas-wall mass transfer, the vapor pressure of the species and the duration of the experiments. This work suggests that SOA yields inferred from chamber experiments could be underestimated up a factor of 2 due to the loss of organic vapors to chamber walls.
\end{abstract}

\section{Introduction}

Secondary organic aerosols (SOAs) represent a major fraction of the fine particulate matter mass (e.g., Jimenez et al., 2009), thus contributing to the physicochemical properties of aerosols and to their impact on human health, climate and visibility. SOAs are produced by condensation of low volatile organic species formed during gaseous oxidation of emitted volatile and intermediate volatility organic compounds (VOCs and IVOCs) (e.g., Kroll and Seinfeld, 2008). Large uncertainties still exist in our understanding of processes leading to SOA formation. To assess and improve our knowledge of SOA formation, atmospheric chambers are widely used to perform controlled experiments of SOA formation from various VOCs and IVOCs. These experiments provide kinetic and thermodynamic data, i.e., kinetic constants, branching ratios and partitioning coefficients (e.g., Atkinson and Arey, 2003; Aschmann et al., 2011), needed to design deterministic SOA models. Experiments performed in atmospheric chambers also provide an ideal data set for the evaluation of deterministic SOA formation models (e.g., Camredon et al., 2010; Valorso et al., 2011; Jenkin et al., 2015) and the development of SOA formation parameterizations for chemical transport models (CTMs) at regional and global scale (e.g., Zhang and Seinfeld, 2013; Cappa and Wilson, 2012; Donahue et al., 2011; Santiago et al., 2012). The presence of walls in atmospheric chambers constitutes, how- 
ever, an artifact for the study of SOA formation. Particles, and thus SOAs, formed during an experiment are known to be deposed on chamber wall surfaces (e.g., McMurry and Grosjean, 1985). This loss of particles has been shown to depend on the size and the concentration of the particles (Bowman et al., 1997). SOA mass is usually corrected assuming that the loss rate during an experiment is a first-order process (e.g., Presto and Donahue, 2006; Pathak et al., 2007) possibly depending on particle size distribution (e.g., Cocker et al., 2001). Recently, few studies have shown that low volatility gaseous species can also be lost onto the chamber wall surfaces (e.g., Kokkola et al., 2014; Loza et al., 2010; Matsunaga and Ziemann, 2010; Yeh and Ziemann, 2014, 2015; Zhang et al., 2014a, 2015). This loss of gaseous organic species on the chamber walls is, however, not yet well characterized.

Matsunaga and Ziemann (2010) have investigated the gaswall partitioning of $C_{8}-C_{16}$ n-alkanes and 1-alkenes, $C_{8}-C_{13}$ 2-alcohols and 2-ketones in Teflon FEP chambers. They observed that the gas-wall partitioning of organic species is a reversible process and that equilibrium can be described by a condensation process. They proposed a parameterization to represent the gas-wall partitioning in which (i) the sorption of gaseous organic species to the wall and their desorption from the wall back to the gas phase are represented by a first-order rate constant (called $k_{\mathrm{gw}}$ and $k_{\mathrm{wg}}$, respectively, hereafter, see Fig. 1) and (ii) the gas-wall partitioning equilibrium follows the Raoult's law, i.e., walls being treated as a phase into which the organic compounds can partition. The temporal variation of the concentration of a semi-volatile organic compound (SVOC) in the gas phase due to the gas-wall transfers is thus given by the following expression:

$$
\left[\frac{\mathrm{d}[\operatorname{SVOC}(\mathrm{g})]}{\mathrm{d} t}\right]_{\mathrm{gas}-\mathrm{wall}}=-k_{\mathrm{gw}}[\operatorname{SVOC}(\mathrm{g})]+k_{\mathrm{wg}}[\operatorname{SVOC}(\mathrm{w})],
$$

where $[\operatorname{SVOC}(\mathrm{g})]$ and $[\operatorname{SVOC}(\mathrm{w})]$ are the concentration of the SVOC in the gas phase and on the wall at a given time respectively. The rate constants are thus linked according to the following equation:

$$
\frac{k_{\mathrm{gw}}}{k_{\mathrm{wg}}}=\frac{\mathrm{RT}}{P^{\text {vap }}} \times \frac{C_{\mathrm{w}}}{M_{\mathrm{w}} \gamma_{\mathrm{w}}},
$$

where $R$ is the ideal gas constant, $T$ is the temperature and $P^{\text {vap }}$ is the vapor pressure of the species. $C_{\mathrm{w}}$ and $M_{\mathrm{w}}$ are an equivalent organic aerosol mass concentration and an equivalent organic aerosol mean molar weight associated with the Teflon film, and $\gamma_{\mathrm{w}}$ is the activity coefficient of the species in the Teflon film. Values for $C_{\mathrm{w}} /\left(M_{\mathrm{w}} \gamma_{\mathrm{w}}\right)$ are empirically derived from chamber observations and Matsunaga and Ziemann (2010) reported values of 9, 20, 50 and $120 \mu$ mole $^{-3}$ for n-alkanes, 1-alkenes, 2-alcohols and 2-ketones, respectively. In these series of experiments, the characteristic times to achieve gas-wall equilibrium $\left(\tau^{*}=1 /\left(k_{\mathrm{gw}}+k_{\mathrm{wg}}\right)\right)$ ranged from less than $8 \mathrm{~min}$ to $1 \mathrm{~h}$. Additional measurements for this

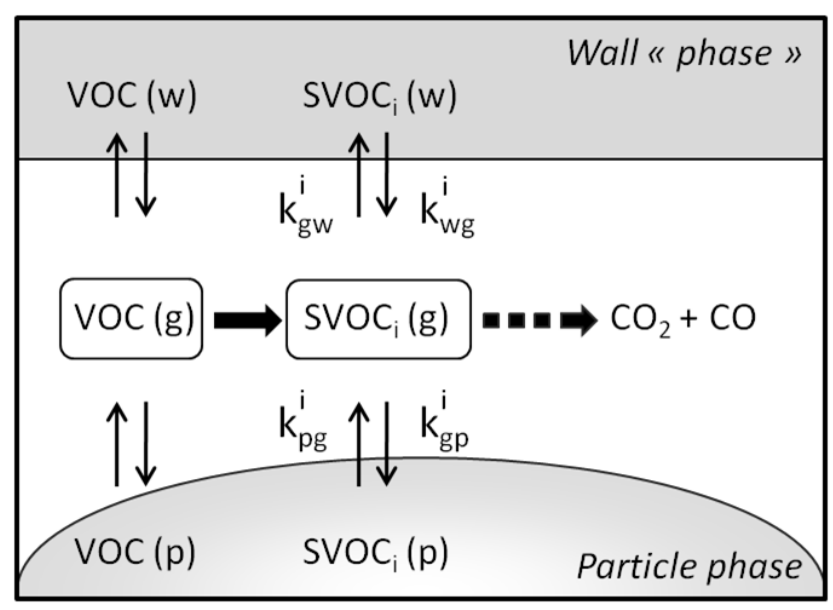

Figure 1. Schematic representation of gas-particle and gas-wall mass transfers of a semi-volatile organic produced during gaseous oxidation of VOCs.

chamber showed values of $\tau^{*}$ up to $100 \mathrm{~min}$ with large variability owing to measurement uncertainties (e.g., Yeh and Ziemann, 2015). For the studied species, the fraction remaining in the gas phase at equilibrium ranged from 0.4 to 0.9 , meaning that $k_{\mathrm{wg}}$ and $k_{\mathrm{gw}}$ are of the same order of magnitude (Eq. 2). In the Matsunaga and Ziemann (2010) parameterization for gas-wall transfers, it is considered that the gas transfers towards the walls are driven by the turbulence inside the chamber and interfacial mass transport through the walls; thus, $k_{\mathrm{gw}}$ is a constant, independent of the compound structure (e.g., Yeh and Ziemann, 2015).

This wall loss is in competition with gas-particle partitioning (see Fig. 1) and the distribution of organic compounds between the gas phase, the particle phase and the walls depends also on the characteristic times associated with the gas-particle mass transfer. Assuming this process is described by two first-order rate constants, the loss rate constant of gaseous organic species to the particle and the evaporation rate constant of condensed species are called $k_{\mathrm{gp}}$ and $k_{\mathrm{pg}}$, respectively. The temporal variation of the concentration of a SVOC in the gas phase due to the gas-particle transfers is thus given by the following expression:

$\left[\frac{\mathrm{d}[\operatorname{SVOC}(\mathrm{g})]}{\mathrm{d} t}\right]_{\text {gas-particle }}=-k_{\mathrm{gp}}[\operatorname{SVOC}(\mathrm{g})]+k_{\mathrm{pg}}[\operatorname{SVOC}(\mathrm{p})]$,

where $[\operatorname{SVOC}(p)]$ is the concentration of the SVOC in the particle phase. Assuming the sorption of gaseous organic species to the particle is to be limited by gas phase diffusion, the first-order loss rate constant of gaseous organic species to the particle, $k_{\mathrm{gp}}$, can be expressed as

$k_{\mathrm{gp}}=4 \pi D_{\mathrm{g}} r_{\mathrm{p}} C_{\mathrm{p}}$,

where $D_{\mathrm{g}}$ is the species gas phase diffusivity, $r_{\mathrm{p}}$ the particle radius and $C_{\mathrm{p}}$ the number of particles per unit volume 
of air (e.g., Seinfeld and Pandis, 2006). This value for $k_{\mathrm{gp}}$ is an upper limit if the gas to particle transfers are limited by interfacial mass transfer and/or particle phase diffusion (Shiraiwa and Seinfeld, 2012). The wall uptake could then be underestimated. At thermodynamic equilibrium, the gasparticle partitioning is expected to follow the Raoult's law (e.g., Pankow, 1994). The rate constants are thus linked according to the following equation:

$\frac{k_{\mathrm{gp}}}{k_{\mathrm{pg}}}=\frac{\mathrm{RT}}{P^{\text {vap }}} \times \frac{C_{\mathrm{aer}}}{M_{\mathrm{aer}} \gamma_{\mathrm{aer}}}$,

where $C_{\text {aer }}$ is the organic aerosol mass concentration, $M_{\text {aer }}$ is the organic aerosol mean molar weight and $\gamma_{\text {aer }}$ is the activity coefficient of the species in the particle phase.

Figure 2 shows the molar fraction $\xi_{\text {phase }}$ of organic compounds in the gas phase, the particle phase and the walls as a function of their volatility (with $\xi_{\text {phase }}=n_{\text {phase }} / n_{\text {tot }}$ ). A continuous distribution of species was considered, having volatilities in the $10^{-12}-10^{-2}$ atm range and assumed to be in the gas phase at $t=0$. The gas-wall transfer rate constants were calculated using the parameterization provided by Matsunaga and Ziemann (2010) for ketones. Here we used an intermediate value for the characteristic time for gas to wall transfer $\left(\tau_{\mathrm{gw}}=1 / k_{\mathrm{gw}}\right)$ of $30 \mathrm{~min}$ to examine the partitioning of the species reported in Fig. 2. Calculations were made using typical conditions encountered in experiments performed in the chamber for which Matsunaga and Ziemann (2010) designed the gaswall parameterization (e.g., Lim and Ziemann, 2009a, b; Matsunaga et al., 2009): $T=298 \mathrm{~K}, C_{\text {aer }}=2000 \mu \mathrm{g} \mathrm{m}^{-3}$, $r_{\mathrm{p}}=0.1 \mu \mathrm{m}$ and $C_{\mathrm{p}}=7 \times 10^{4} \mathrm{~cm}^{-3}$. The distributions were computed using $D_{\mathrm{g}}=0.03 \mathrm{~cm}^{2} \mathrm{~s}^{-1}, \quad M_{\text {aer }}=200 \mathrm{~g} \mathrm{~mol}^{-1}$ and $\gamma_{\mathrm{aer}}=1$. These conditions lead to the following mass transfer rate constants: $k_{\mathrm{gp}}=2.6 \times 10^{-1} \mathrm{~s}^{-1}$, $k_{\mathrm{pg}}=1.1 \times 10^{6} P^{\text {vap }} \mathrm{s}^{-1} \mathrm{~atm}^{-1}, k_{\mathrm{gw}}=5.6 \times 10^{-4} \mathrm{~s}^{-1}$ and $k_{\mathrm{wg}}=1.9 \times 10^{-4} P^{\mathrm{vap}} \mathrm{s}^{-1} \mathrm{~atm}^{-1}$. Results are shown at various times: $6 \mathrm{~min}$ (time length of the alkene experiments presented by Matsunaga et al., 2009), $1 \mathrm{~h}$ (time length of the alkane experiments in Lim and Ziemann, 2009a, b), $20 \mathrm{~h}$ (upper value for the length of a chamber experiment) and at equilibrium. At $6 \mathrm{~min}$, species with volatility greater than $10^{-4} \mathrm{~atm}$ remained in the gas phase and those having volatility less than $10^{-8} \mathrm{~atm}$ totally partitioned into the particle phase. Between these two values of saturation vapor pressure, the fraction of organic species lost into the wall is greater than $10 \%$, with a fraction in the wall reaching $15 \%$ for organic species having a saturation vapor pressure equal to $10^{-6} \mathrm{~atm}$. At $1 \mathrm{~h}$, wall losses increase substantially. The fraction of species lost on the wall reaches at least $10 \%$ in the $10^{-8}-10^{-5}$ atm vapor pressure range. This fraction peaks at $65 \%$ for species with vapor pressures around $10^{-6} \mathrm{~atm}$. At $20 \mathrm{~h}$, the volatility range showing a substantial uptake by the wall spans 4 orders of magnitude, from $10^{-9}$ to $10^{-5} \mathrm{~atm}$. At equilibrium, the fraction lost to the wall exceeds $90 \%$ for species having a vapor pressure under $10^{-7} \mathrm{~atm}$. For high volatility species, equilibrium is achieved on a short timescale (below $6 \mathrm{~min}$ ): the gas-particle-wall partitioning is under a thermodynamic control. By contrast, for low volatility species, the distributions change with time and the gasparticle-wall partitioning is under kinetic control. Note that the range of $\mathrm{SVOC}+\mathrm{OH}$ rate constants is between $10^{-12}$ and $10^{-10} \mathrm{molec}^{-1} \mathrm{~cm}^{3} \mathrm{~s}^{-1}$. For typical experiments, OH concentrations lie between $10^{6}$ and $10^{7}$ molec $\mathrm{cm}^{-3}$. The chemical loss rates due to $\mathrm{OH}$ oxidation therefore range between $10^{-6}$ and $10^{-3} \mathrm{~s}^{-1}$. The gas to wall transfer rate of a given SVOC could be of the same order of magnitude as the $\mathrm{OH}$ loss rates (for $\tau_{\mathrm{gw}}=1 \mathrm{~h}, k_{\mathrm{gw}}=2.8 \times 10^{-4} \mathrm{~s}^{-1}$ ); wall loss could thus be in competition with $\mathrm{OH}$ oxidation. Wall loss is therefore expected to significantly impact SOA measurements, being in competition with the gas-particle partitioning of SVOCs and acting as a sink for gaseous intermediates that ultimately produce SOA contributors after additional oxidation steps.

The objectives of this study are (i) to quantify the potential impact of chamber walls on the loss of gaseous organics and therefore SOA formation, (ii) to explore the structure of organic species mainly impacted by this loss and (iii) to assess our current understanding of SOA formation from various structures of VOCs and IVOCs. The methodology used here consists of simulating a selected set of experiments using an explicit description of SOA formation (i.e., gaseous oxidation and gas-particle partitioning). The Generator for Explicit Chemistry and Kinetics of the Organics in the Atmosphere (GECKO-A) (e.g., Aumont et al., 2005; Camredon et al., 2007; Valorso et al., 2011) has been used to generate the explicit gaseous chemical schemes and the properties required to describe the gas-particle partitioning (i.e., the saturation vapor pressure of all species). Alkanes and alkenes are an important class of compounds to study fundamental chemical reactions involved in atmospheric oxidation and the effects of molecular structure on the formation of low volatility compounds, which could form SOAs. The set of smog chamber experiments performed in the Ziemann lab at the UC Riverside Air Pollution Research Center (APRC) has been selected as it includes a large set of alkane and alkene structures (of varying carbon chain length and including cyclic, linear and branched species) (e.g., Lim and Ziemann, 2009a, b; Matsunaga et al., 2009). Furthermore, the Matsunaga et al. (2009) parameterizations of gaseous organic species wall loss have been fitted for this specific chamber (e.g., Matsunaga and Ziemann, 2010). Experimental conditions are described in Sect. 2. Section 3 is devoted to describing the modeling tool and setup. In Sect. 4, the results of the comparison between the measured and simulated SOA yields are presented and the GECKO-A chemical mechanisms are used to identify SOA products likely affected the by gas-wall partitioning process. 

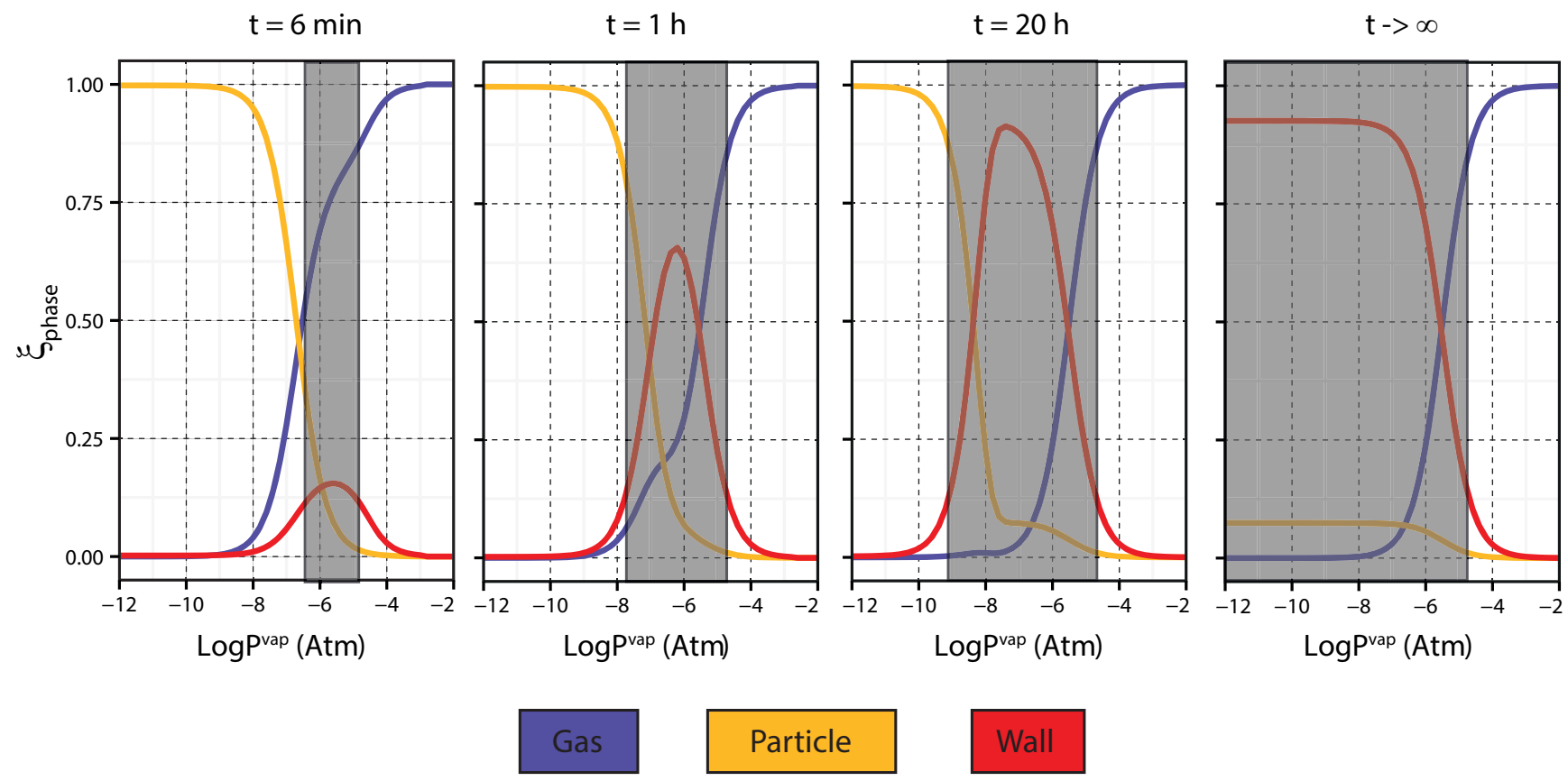

\section{Particle}

Figure 2. Time evolution of the fraction in the gas, particle and wall phases as a function of the vapor pressure for a continuous distribution of species considered to be initially only in the gas phase. Grey zones represent the volatility range impacted by wall losses at a molar fraction higher than $10 \%$.

\section{Experimental conditions}

The experimental data set includes linear, branched and cyclic alkanes, linear and 2-methyl 1-alkenes and internal alkenes with a number of carbon atoms ranging from 7 to 17. All the experiments were performed in the UC Riverside APRC chamber under high $\mathrm{NO}_{x}$ conditions (5-10 ppm), dry conditions $(\mathrm{RH}<1 \%)$ and at ambient temperature. The $\mathrm{CH}_{3} \mathrm{ONO}$ photolysis was used to produce $\mathrm{OH}$ radicals. Organic seeds were introduced to enhance gas-particle partitioning. Experiments were typically carried out with $1 \mathrm{ppm}$ of hydrocarbon $(0.5 \mathrm{ppm}$ for precursors with 17 carbon atoms), 5 or $10 \mathrm{ppm}$ each of $\mathrm{CH}_{3} \mathrm{ONO}$ and $\mathrm{NO}$ and 200 $400 \mathrm{\mu g} \mathrm{m}^{-3}$ of DOS (dioctylsebacate) as organic seeds. The precursors and initial seeds were introduced into the chamber and left in the dark to achieve gas-wall partitioning equilibrium. The oxidation starts when the black-light lamps are turned on to initiate the $\mathrm{CH}_{3} \mathrm{ONO}$ photolysis. The temporal evolutions of the concentration of precursor, $\mathrm{NO}_{x}$ or $\mathrm{O}_{3}$ during the experiment are not available. The quantity of reacted hydrocarbon $(\triangle \mathrm{HC})$, is equal to

$\Delta \mathrm{HC}=[\mathrm{HC}]_{\mathrm{tot}}^{i}-[\mathrm{HC}]_{\mathrm{tot}}^{f}$,

where $[\mathrm{HC}]_{\mathrm{tot}}^{i}$ and $[\mathrm{HC}]_{\text {tot }}^{f}$ are the total mass concentration of hydrocarbon in the chamber at the beginning (i.e., the injected amount) and the end (i.e., the sum of the amount in the gas phase, particle phase and on the wall) of the experiment, respectively. $\triangle \mathrm{HC}$ was calculated experimentally using the initial (before turning the light on, $[\mathrm{HC}]_{\mathrm{gas}}^{\mathrm{on}}$ ) and final (after turning the lamps off, $[\mathrm{HC}]_{\text {gas }}^{\text {off }}$ ) measured concentrations of the precursor in the gas phase once the gas-aerosol-wall equilibrium had been achieved as

$\Delta \mathrm{HC}=\left(1-\frac{[\mathrm{HC}]_{\mathrm{gas}}^{\mathrm{off}}}{[\mathrm{HC}]_{\mathrm{gas}}^{\mathrm{on}}}\right)[\mathrm{HC}]_{\mathrm{tot}}^{i}$.

The experimental $\triangle \mathrm{HC}$ are reported in Fig. 6 for all the experiments. A detailed description of these experiments can be found in Lim and Ziemann (2009b), Matsunaga (2009) and Matsunaga et al. (2009). Measured injected concentrations and environmental conditions for each experiment are summarized in Table 1.

\section{Model description and simulation setup}

\subsection{Gaseous and condensed phase chemical schemes}

An explicit description of long-chain hydrocarbon oxidation processes up to the final production of $\mathrm{CO}_{2}$ involves millions of reactions (e.g., Aumont et al., 2005). Such explicit chemical schemes are too large to be written manually. The GECKO-A computer program has been developed to overcome this difficulty. This tool is used here to generate explicit chemical schemes for the long-chain hydrocarbons.

The GECKO-A tool generates chemical schemes for a given precursor on the basis of a prescribed protocol. Re- 
Table 1. Measured injected concentrations and environmental conditions of the experiments.

\begin{tabular}{|c|c|c|c|c|c|}
\hline Exp. & $\begin{array}{l}{[\mathrm{HC}]_{0}} \\
(\mathrm{ppm})\end{array}$ & $\begin{array}{l}{[\mathrm{NO}]_{0}} \\
(\mathrm{ppm})\end{array}$ & $\begin{array}{l}{\left[\mathrm{CH}_{3} \mathrm{ONO}\right]_{0}} \\
(\mathrm{ppm})\end{array}$ & $\begin{array}{l}\text { [DOS seeds] } \\
\left(\mu \mathrm{g} \mathrm{m}^{-3}\right)\end{array}$ & $\begin{array}{l}J_{\mathrm{NO}_{2}}\left(\min ^{-1}\right) / \\
\text { time exposure }(\min )\end{array}$ \\
\hline Linear alkanes ${ }^{\mathrm{a}}\left(\mathrm{C}_{7}-\mathrm{C}_{17}\right)$ & $0.5-1$ & 10 & 10 & $90-400$ & $0.38 / 60$ \\
\hline Cyclic alkanes ${ }^{\mathrm{a}}\left(\mathrm{C}_{6}-\mathrm{C}_{15}\right)$ & 1 & 10 & 10 & $150-300$ & $0.38 / 60$ \\
\hline Branched alkanes $^{\mathrm{a}}\left(\mathrm{C}_{12}\right)$ & 1 & 10 & 10 & $100-200$ & $0.38 / 60$ \\
\hline 1-Alkenes ${ }^{\mathrm{b}}\left(\mathrm{C}_{8}-\mathrm{C}_{17}\right)$ & $0.5-1$ & 5 & 5 & 200 & $0.14 / 6$ \\
\hline Internal alkenes ${ }^{\mathrm{b}}\left(\mathrm{C}_{14}-\mathrm{C}_{17}\right)$ & $0.3-1$ & 5 & 5 & 200 & $0.14 / 6$ \\
\hline 2-Methyl-1-alkenes ${ }^{\mathrm{c}}\left(\mathrm{C}_{9}-\mathrm{C}_{15}\right)$ & 1 & 5 & 5 & 200 & $0.14 / 6$ \\
\hline
\end{tabular}

${ }^{a}$ Lim and Ziemann (2009a); ${ }^{\text {b }}$ Matsunaga et al. (2009) and ${ }^{\mathrm{c}}$ Matsunaga (2009).

action pathways and kinetic data are assigned from experimental data if available or structure activity relationships (SARs) if not. The protocol implemented in GECKO-A is described in Aumont et al. (2005), with chemistry updates performed by Aumont et al. (2012, 2013). The evolution of alkoxy radicals through decomposition, isomerization or stabilization chemical pathways characterizes the functionalization or the fragmentation of an organic species during its oxidation. Therefore, the fate of alkoxy radicals determines SOA formation. The SAR developed by Atkinson (2007) is used in GECKO-A to estimate the rate coefficients for alkoxy radical isomerization based on experimental data. Vereecken and Peeters $(2009,2010)$ have recently developed SARs based on quantum chemical calculations to estimate the rate coefficient of both alkoxy radical decomposition and $\mathrm{H}$-migration. These new SARs for alkoxy radical decomposition and isomerization have also been implemented in GECKO-A.

No reactions were previously assumed in the condensed phase. Dihydrofurans (DHFs) have been found in equilibrium with 1,4-hydroxycarbonyls $(1,4 \mathrm{HCs})$ in the gas phase (Cavalli et al., 2000; Martin et al., 2002). These oxidation products of DHFs have been shown to contribute largely to the composition of SOAs formed during alkane and alkene oxidation (e.g., Gong et al., 2005; Lim and Ziemann, 2009a; Zhang et al., 2014b). DHFs are produced by the heterogeneous cyclization of $1,4 \mathrm{HCs}$ into cyclic hemiacetals (CHAs) that will dehydrate to form DHF (e.g., Martin et al., 2002; Atkinson et al., 2008). DHF formation is expected to be significant during SOA formation from alkane and alkene oxidation as $1,4 \mathrm{HC}$ are produced at high yields during the first gaseous oxidation step of these precursors. The formation of DHF is therefore expected to significantly influence the SOA mass and composition. The heterogeneous formation of DHF has therefore been added to the GECKO-A protocol.

The DHF formation protocol is designed based on the Lim and Ziemann (2009c) mechanism, which considers (i) the cyclization of the condensed 1,4HCs into CHAs and (ii) the dehydration of the CHAs forming the DHFs with (iii) hydration allowed for the reverse reaction (see Fig. 3). Lim and Ziemman $(2009 \mathrm{c})$ provided an effective uptake coefficient of 0.5 for the $1,4 \mathrm{HC}(\mathrm{g}) \rightarrow \mathrm{CHA}(\mathrm{p})$ cyclization meaning that

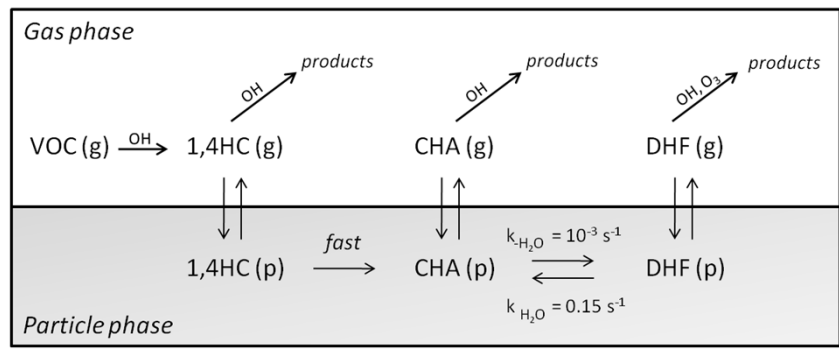

Figure 3. Representation of DHF formation in the GECKO-A protocol.

the rate of the transformation is collision limited. Here, we considered explicitly the $1,4 \mathrm{HC}(\mathrm{g}) \leftrightarrow 1,4 \mathrm{HC}(\mathrm{p})$ mass transfers and assumed that the $1,4 \mathrm{HC}(\mathrm{p}) \rightarrow \mathrm{CHA}(\mathrm{p})$ cyclization is fast (see Fig. 3). This model configuration is an upper value for the cyclization process of 1,4HCs. Furthermore, Lim and Ziemann (2009c) optimized a value of $10^{-3} \mathrm{~s}^{-1}$ for the dehydration rate constant and values between 0.002 and $0.15 \mathrm{~s}^{-1}$ for the hydration rate constant. The rate constant for the hydration reaction is set in GECKO-A protocol to the higher value obtained for the set of n-alkane experiments (that for tetradecane under dry conditions), $k_{\mathrm{H}_{2} \mathrm{O}}=0.15 \mathrm{~s}^{-1}$. This process has been shown experimentally to occur not only in the organic particle phase but also on Teflon wall surfaces (Atkinson et al., 2008). The DHF formation mechanism was thus considered in the GECKO-A protocol in the particle phase as well as on the walls. Gas-particle and gas-wall mass transfers and gaseous chemistry of $1,4 \mathrm{HC}, \mathrm{CHA}$ and DHF were treated automatically with the GECKO-A protocol (see Fig. 3).

\subsection{Dynamic representation of mass transfers}

In the previous version of GECKO-A, the partitioning between the gaseous and the aerosol phases was described assuming equilibrium (e.g., Camredon et al., 2007; Lee-Taylor et al., 2015). In order to take into account the competition between the aerosols and walls for the condensation of gaseous organic compounds, the partitioning has now been imple- 
mented dynamically. The gas-particle transfer is considered limited by the gas phase diffusion. Equation (4) is used to represent the rate constant of the gas-particle mass transfer, $k_{\mathrm{gp}}$. The species gas phase diffusivity, $D_{\mathrm{g}}$, is derived using the kinetic theory of gases, $D_{\mathrm{g}}=\left\langle c_{i}\right\rangle \lambda / 2$, where $\left\langle c_{i}\right\rangle$ is the mean velocity of gaseous species $i$ and $\lambda$ is the mean free path (Seinfeld and Pandis, 2006). During the experiments, SOA mass formed from nucleation process accounts for less than $10 \%$ to the total measured SOA mass (see Lim and Ziemann, 2005). We thus considered here that (i) the particle number $C_{\mathrm{p}}$ remains unchanged during the course of an experiment and equal to the number of initial DOS seeds and (ii) the particle radius $r_{\mathrm{p}}$ was growing because of the aerosol mass increase, $r_{\mathrm{p}}$, being calculated assuming spherical particles and a particle density of $1 \mathrm{~g} \mathrm{~cm}^{-3}$ ( $\mathrm{Lim}$ and Ziemann, 2009b; Matsunaga et al., 2009). The particle-gas rate constant $k_{\mathrm{pg}}$ was calculated according to Eq. (5). Vapor pressures of organic species were estimated using the Nannoolal et al. (2008) method combined with the Nannoolal et al. (2004) method for boiling-point estimates. Particles were considered as a homogeneous and ideal phase (i.e., $\gamma_{i}=1$ ).

Gas-wall partitioning was implemented in the GECKOA protocol according to the parameterization of Matsunaga and Ziemann (2010) (see Eq. 2). Sensitivity tests were performed on both $\tau_{\mathrm{gw}}$ and $C_{\mathrm{w}} /\left(M_{\mathrm{w}} \gamma_{\mathrm{w}}\right)$ values. Three sets of simulations were therefore performed for $\tau_{\mathrm{gw}}$ using 10, 30 and $60 \mathrm{~min}$ to encompass the observed values. Similarly, two sets of simulations were performed for the $C_{\mathrm{w}} /\left(M_{\mathrm{w}} \gamma_{\mathrm{w}}\right)$ parameter using either the values given in Matsunaga and Ziemann (2010) for ketones $\left(120 \mu\right.$ mole $\left.^{-3}\right)$ or 2-alcohol $\left(50 \mu \mathrm{mole}^{-3}\right)$ for all oxygenated species. For the parent hydrocarbon, the values of 9 and $20 \mu$ mole $^{-3}$ were used for alkanes and alkenes, respectively.

\subsection{Reduction of chemical schemes}

The size of the explicit oxidation scheme generated by the GECKO-A tool rises exponentially with the carbon number of the precursor (Aumont et al., 2005). Solving fully explicit chemical schemes requires excessive computer resources. The chemical schemes were therefore shrunk using the simplifications discussed below.

Experiments were carried out under high $\mathrm{NO}_{x}$ levels $(\sim 10 \mathrm{ppm})$. The reaction of peroxy radicals with $\mathrm{NO}$ is dominant compared to those with $\mathrm{HO}_{2}$ and $\mathrm{RO}_{2}$. The reactions of $\mathrm{RO}_{2}$ with $\mathrm{HO}_{2}$ and with other $\mathrm{RO}_{2}$ were therefore ignored in the chemical schemes. The length of experiments was short ( $6 \mathrm{~min}$ for alkenes or $1 \mathrm{~h}$ for alkanes). The contribution of organic species formed after several oxidation steps can thus be neglected. The generated chemical schemes include the description of the formation of organic species up to five generations. Moreover organic species having a low vapor pressure can be considered as mainly present in the condensed phases. The inclusion of their gaseous chemistry in the chemical schemes is thus not needed. Gaseous

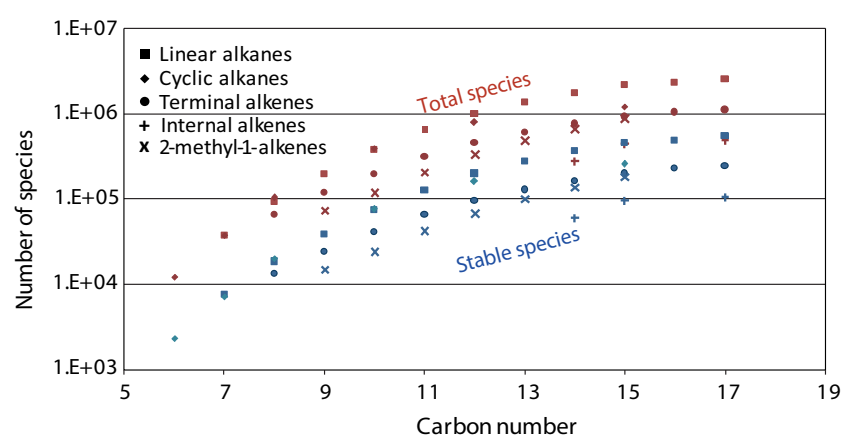

Figure 4. Number of stable (blue) and total organic species (red) in the reduced chemical schemes generated with GECKO-A as a function of the number of carbons in the parent compound for the studied precursor's families.

reactions were not considered in the chemical schemes for species having a vapor pressure lower than $10^{-13} \mathrm{~atm}$, being negligible in the gaseous phase under these experimental conditions $\left(C_{\text {aer }}\right.$ varying between 100 and $\left.6000 \mu \mathrm{g} \mathrm{m}^{-3}\right)$. Gas-particle and gas-wall mass transfers were considered for stable (i.e., non-radical) species only. Figure 4 shows the number of stable and total organic species in these reduced chemical schemes, as a function of the number of carbon atoms in the parent compound for the studied precursor's families.

\subsection{Simulation setup}

The explicit chemical schemes generated by GECKO-A were implemented in a box model. Time integration of chemical schemes and mass transfers is solved using the two-step solver (Verwer et al., 1994, 1996). Photolysis frequencies for inorganic and organic species for a black-light spectrum were calculated using cross section and quantum yields described in Aumont et al. (2005). The photolysis of methyl nitrite was calculated using a quantum yield equal to 0.33 (Heicklen, 1988) and the absorption cross section measured by Taylor et al. (1980). All the photolysis frequencies were scaled based on the measured $J_{\mathrm{NO}_{2}}$. Simulations were initialized with the measured concentrations listed in Table 1. Similar to the experimental conditions, a 60 min period in the dark is first simulated to enforce gas-wall equilibrium for the parent hydrocarbon before starting the oxidation.

Simulated temporal evolutions of the decays of $n$-alkane in the gas phase are represented in Fig. 5 with and without considering gas-wall partitioning. Linear alkanes having more than 13 carbon atoms show a drop in the gaseous concentration early in the simulation mainly due to the chamber wall partitioning. As expected, this drop increases with the chain length due to the decrease of vapor pressure. Similar trends are observed for the other series of precursors. These behaviors indicate that a significant fraction of the initial hydrocarbon load can be removed into the wall for IVOC precursors. 


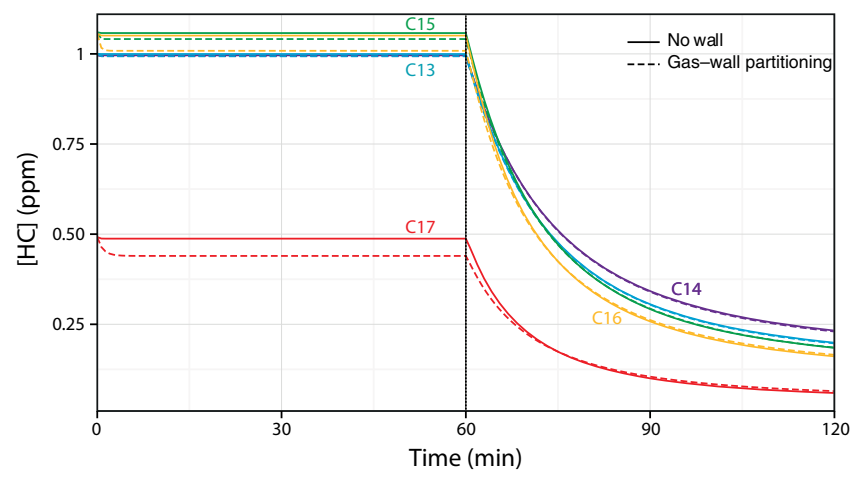

Figure 5. Simulated temporal evolutions of the decays of n-alkanes in the gas phase without (solid line) and with (dashed line) gaswall partitioning. The dotted line at $60 \mathrm{~min}$ corresponds to the time at which the lights are turned on.

Furthermore, it is noteworthy that for these species the gaswall partitioning equilibrium is achieved within a few minutes, a timescale short enough to not observe that process during most of the chamber experiments.

The measured mass of $\triangle \mathrm{HC}$ was used to assess the simulation setup. Figure 6 shows the comparison between the measured and simulated $\Delta \mathrm{HC}$ mass. The values are displayed by chemical family and as a function of carbon chain length or number of methyl groups on the carbon backbone. Within each family, the amount of reacted compound typically grows with the size of the carbon skeleton. This behavior is consistent with the corresponding increase of the hydrocarbon $+\mathrm{OH}$ rate constant with the size of the carbon skeleton (e.g., Kwok and Atkinson, 1995). For the whole set of simulations, $\triangle \mathrm{HCs}$ are well reproduced by the model. Hence, the simulation setups are considered suitable to represent experimental conditions.

\section{Results and discussions}

\subsection{Comparison between measured and simulated SOA yields}

SOA yield is defined as the ratio of SOA mass produced to the mass of $\triangle \mathrm{HC}$. A comparison of the experimental and the simulated final SOA yields is presented in Fig. 7 (i.e., after $1 \mathrm{~h}$ of experiment for alkane and $6 \mathrm{~min}$ for alkene). Results are reported as a function of the number of carbon atoms or branching in the parent hydrocarbon. Experimental data are displayed as given in the experimental papers by Lim and Ziemann (2009b), Matsunaga (2009) and Matsunaga et al. (2009). These published SOA yields were corrected from aerosol wall loss, considering a first-order process and no interaction between the gas and the wall deposited particles.

Simulations were performed with and without wall loss taken into account for the organic vapors (see Fig. 7). Simulations reported in Fig. 7 were obtained us- ing $C_{\mathrm{w}} /\left(M_{\mathrm{w}} \gamma_{\mathrm{w}}\right)=120 \mu$ mole $\mathrm{m}^{-3}$ for all secondary species and for $\tau_{\mathrm{gw}}$ using 10,30 and $60 \mathrm{~min}$. Similar results were obtained for the simulations performed with $C_{\mathrm{w}} /\left(M_{\mathrm{w}} \gamma_{\mathrm{w}}\right)=50 \mu$ mole $^{-3}$ (see Fig. S1 in the Supplement). Simulations presented in Fig. 7 were carried out using the SAR developed by Atkinson (2007) to describe the alkoxy chemistry (hereafter denoted ATK simulations). A set of simulations was also performed using the Vereecken and Peeters $(2009,2010)$ SARs for the estimation of the alkoxy decomposition rates and the alkoxy isomerization rates (hereafter denoted VER simulations). Figure S2 in the Supplement shows the comparison of the results obtained with ATK and VER, which is discussed below.

For the alkane series, the experimental trends are well captured by the model. In particular, both the simulated and observed SOA yields (i) increase with the carbon number of the precursor, (ii) are higher for a cyclic compared to a linear structure and (iii) decrease with the number of methyl groups on the carbon skeleton. This behavior is mostly driven by the fate of alkoxy radicals. While decomposition (i.e., C$\mathrm{C}$ bond breaking) pathways of linear alkoxy radicals lead to molecules with a smaller carbon backbone (see Fig. 9), the decomposition of cyclic alkoxy radicals preserves the size of the carbon backbone. Similarly, decomposition is enhanced for branched alkoxy radicals (e.g., Lim and Ziemann et al., 2009a). This effect is well represented in the simulations, as discussed in Aumont et al. (2013). Figure 7 shows that the SOA yields simulated without wall loss taken into account are systematically overestimated. A better agreement is obtained when the partitioning of organic species to the wall is considered in the model. Decreasing characteristic time of the gas to wall mass transfer decreases the simulated SOA yields (see Fig. 7). The best agreement is obtained for the lower value of $\tau_{\mathrm{gw}}(10 \mathrm{~min})$ with SOA-yield reductions ranging from a factor of 1.25 to 2 . Note that a change in gas-wall equilibrium value does not affect these results (see Fig. S1). Besides, using the lower value of $C_{\mathrm{w}} /\left(M_{\mathrm{w}} \gamma_{\mathrm{w}}\right)$ $\left(50 \mu\right.$ mole $^{-3}$ ) increases SOA yield by less than $15 \%$ (see Fig. S1). As discussed above, for a simulation lasting $1 \mathrm{~h}$, the gas-particle partitioning outweighs the gas-wall partitioning for low volatility species, leading to a rather low sensitivity to the wall properties. Partitioning is therefore rather under the kinetic control than the thermodynamic control.

The experimental trends are also well captured by the model for the alkene series. Simulations and experimental observations show that SOA yields (i) increase with the number of carbon atom in the parent hydrocarbon and (ii) are higher for 1-alkenes than for internal alkenes and 2-methyl1 -alkene. These trends are largely controlled by the fate of the $\beta$-hydroxyalkoxy radicals resulting from $\mathrm{OH}$ addition on the $\mathrm{C}=\mathrm{C}$ bond. In particular, typically one carbon atom is lost from the backbone during the fragmentation of alkoxy radicals produced from 1-alkenes, while in the case of internal alkenes the carbon skeleton is broken in the middle of the molecule, ultimately leading to volatile products and 


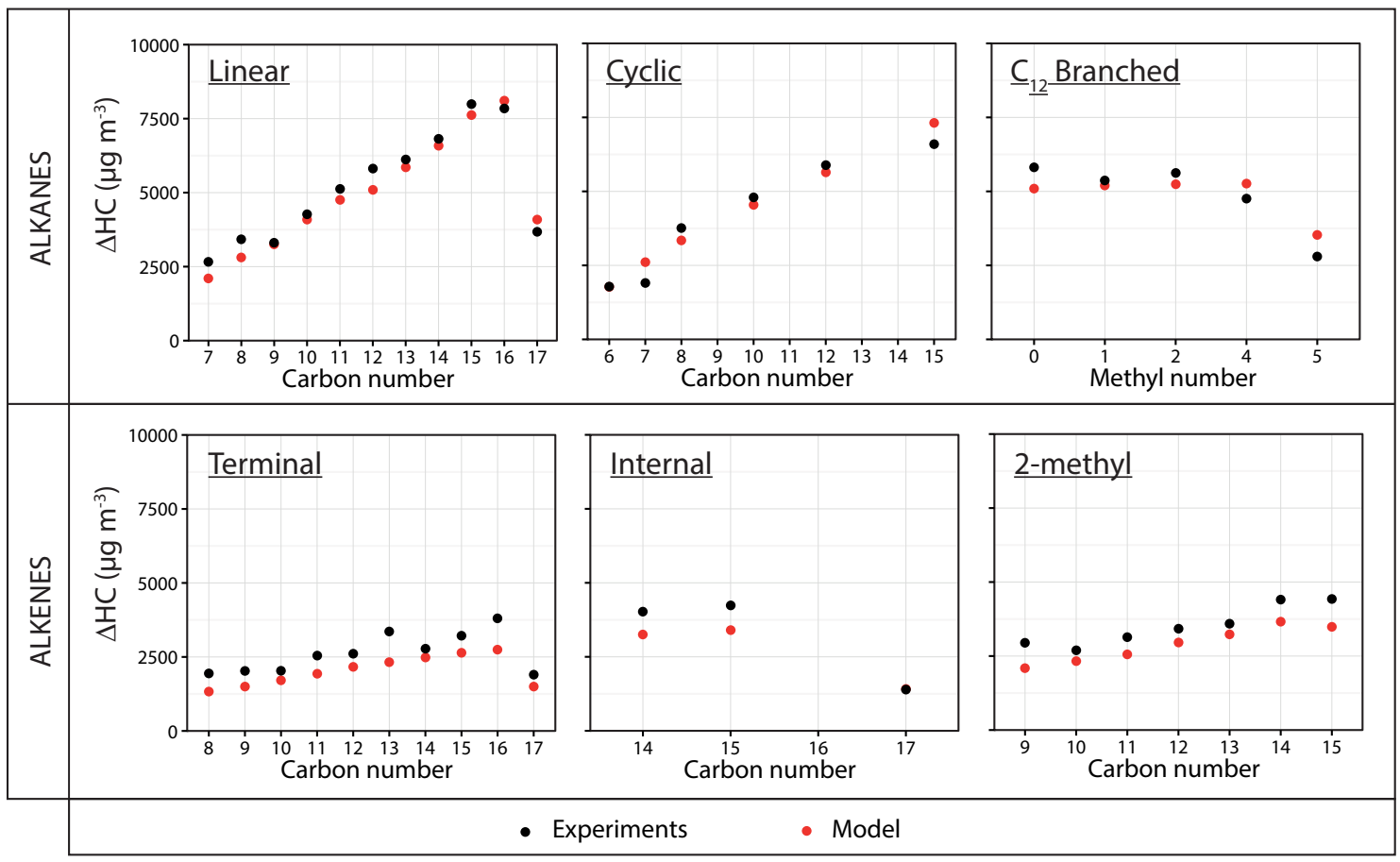

Figure 6. Comparison between the measured (black) and the simulated (red) $\Delta \mathrm{HC}$ mass for the different chemical families as a function of carbon chain length or number of methyl groups of the carbon backbone.

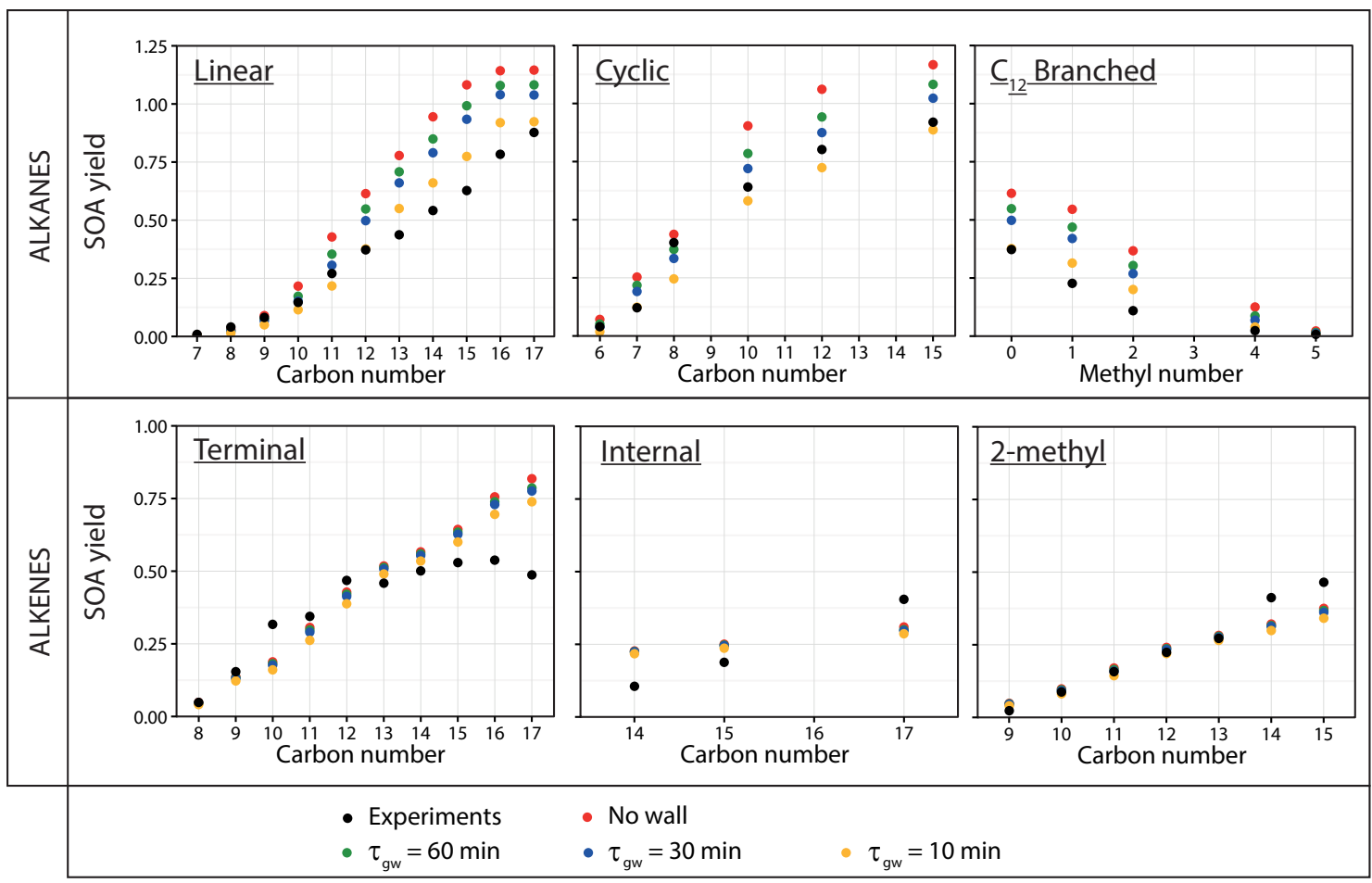

Figure 7. Comparison between measured (black) and simulated SOA yields for the different chemical families as a function of carbon chain length or presence of methyl groups on the carbon backbone. Simulations are shown without wall loss (red) and with wall loss using a value of $C_{\mathrm{w}} /\left(M_{\mathrm{w}} \gamma_{\mathrm{w}}\right)=120 \mu \mathrm{mole}^{-3}$ for all secondary species and a $\tau_{\mathrm{gw}}$ of $10 \mathrm{~min}$ (yellow), $30 \mathrm{~min}$ (blue) or $60 \mathrm{~min}$ (green). 


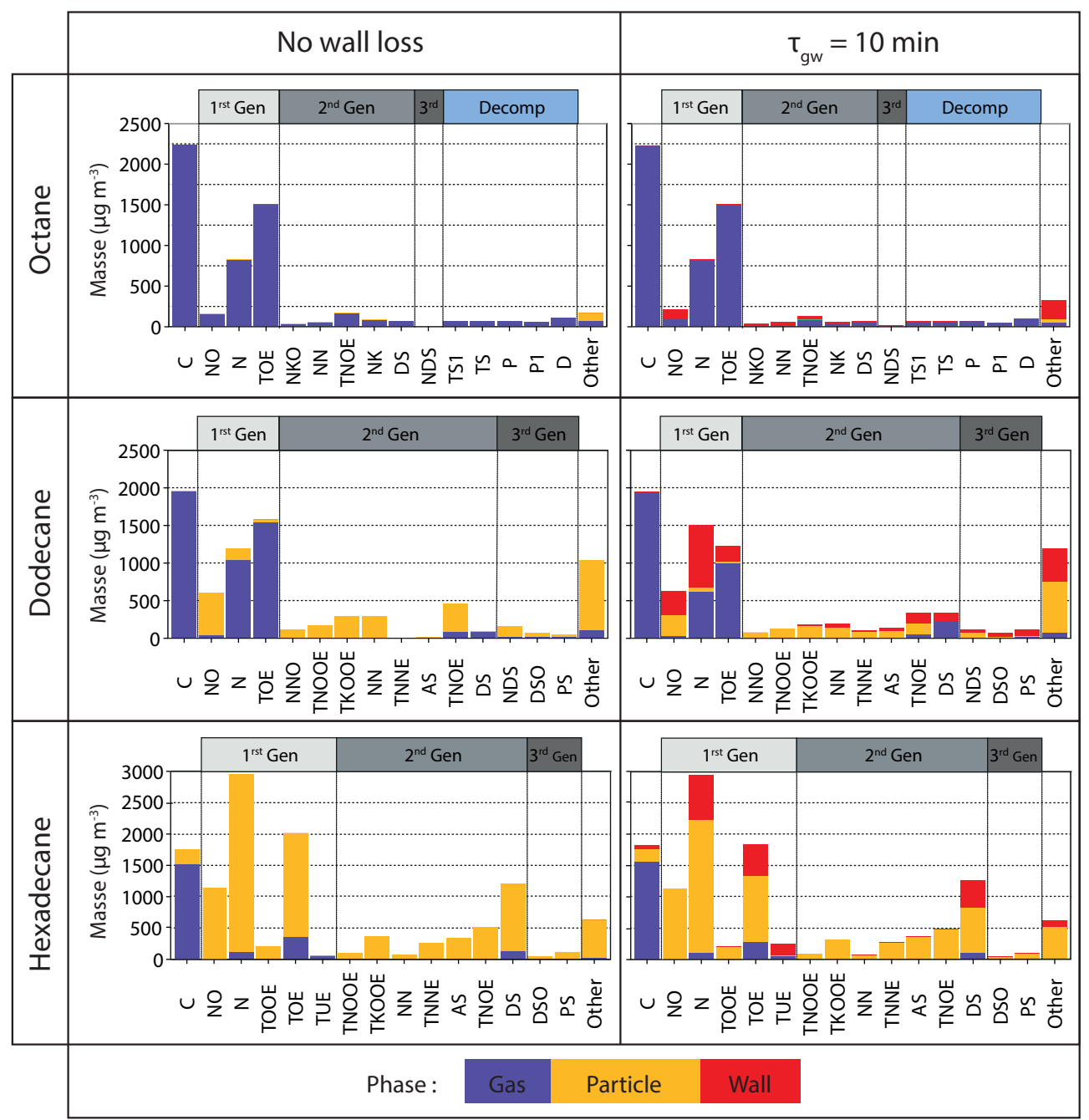

Figure 8. Distribution of the top 15 species between the gas phase (purple), the particle phase (yellow) and the walls (red) at the end of the simulations for n-octane $\left(\mathrm{C}_{8}\right)$, n-dodecane $\left(\mathrm{C}_{12}\right)$ and $\mathrm{n}$-hexadecane $\left(\mathrm{C}_{16}\right)$. Simulated results are reported in mass concentrations (in $\mu \mathrm{g} \mathrm{m}^{-3}$ of air or equivalent for the Teflon phase) for simulations conducted without wall loss (left panel) and with partitioning to the wall using $\tau_{\mathrm{gw}}=10$ min and $\mathrm{C}_{\mathrm{w}} /\left(M_{\mathrm{w}} \gamma_{\mathrm{w}}\right)=120 \mu$ mole $\mathrm{m}^{-3}$ (right panel).

therefore lower SOA yields. For the simulations with $C_{<13}$ alkene precursors, the simulated SOA yields are consistent with experimental data with a mean bias of less than $30 \%$. However, the model/observation agreements for larger parent hydrocarbons depend on the considered alkene series: for 1-alkenes, the simulated SOA yields are overestimated and the discrepancies rise with the size of the precursors; for internal alkenes the simulated SOA yields are relatively constant while the experimental yields show a significant growth with the carbon chain length; and for 2-methyl-1-alkenes, the model underestimates SOA yields. For these 6 min experiments, simulation results appear to be rather insensitive to the wall loss of organic vapors (see Fig. 7), even for simulations performed using the lowest value of $\tau_{\mathrm{gw}}(10 \mathrm{~min})$ with SOA-yield reductions less than a factor of 1.1.
A comparison of the ATK and VER simulation results is shown in Fig. S2. The VER configuration of the model produces lower SOA yields compared to the ATK configuration. For the alkane simulations, the differences are small, with both SAR predicting similar branching ratios for the simple alkoxy chemical structures produced during the first generations. A larger effect is, however, observed in the simulated SOA yields for alkenes, reaching for instance a factor of 2 for the $\mathrm{C}_{11}$ 1-alkene. This effect is, in particular, due to different predictions of the branching ratios of $\beta$-hydroxyalkoxy radicals, a key chemical structure produced from $\mathrm{OH}$ addition to the $\mathrm{C}=\mathrm{C}$ bond. For the conditions examined in this study, the reaction of $\beta$-hydroxyalkoxy radicals with $\mathrm{O}_{2}$ is negligible compared to the isomerization and decomposition routes (Atkinson, 2007). The branching ratios predicted for these two pathways according to the ATK and VER configurations 
are reported in Table 2 for selected generic structures produced from the oxidation of terminal, internal and 2-methyl alkenes. The VER configuration leads to a larger fraction of decomposition than the ATK configuration, which is consistent with lower simulated SOA yields for the VER configuration compared to the ATK one. Table 2 also reports experimentally derived branching ratios from measurements of the oxidation products (Matsunaga et al., 2009; Aschmann et al., 2010; Ziemann, 2011). These experimental results suggest that the isomerization routes are underestimated in both the ATK and VER configurations for $\mathrm{OH}+$ alkene systems. The implementation of organic vapor wall loss or the use of a different structure activity relationship to estimate the fate of the alkoxy radicals does not fully explain the discrepancies between the model and the observations for the alkene series. Some chemical pathways are clearly not well represented or missing in the GECKO-A mechanism (e.g., autoxidation processes, dimers formation and/or heterogeneous oxidation processes in the particle phase). The measurement of final SOA yields does not provide enough insights to identify the source of the model/measure discrepancies, additional information on SOA composition would be needed.

\subsection{Gas-wall partitioning impacts on SOA composition}

Simulations performed with the GECKO-A mechanisms were used to examine which species are prone to partition with the chamber walls. Figure 8 presents the distribution of the top 15 species in the gas, particles and wall (i.e., Teflon) phases for various experiments. Simulated results are reported at the end of the experiments in mass concentrations (in $\mu \mathrm{g} \mathrm{m}^{-3}$ of air or equivalent for the Teflon phase) for both cases: without (left panel) and with partitioning to the wall using $\tau_{\mathrm{gw}}=10 \min$ and $C_{\mathrm{w}} /\left(M_{\mathrm{w}} \gamma_{\mathrm{w}}\right)=120 \mu$ mole $^{-3}$ (right panel). Results in Fig. 8 are reported for n-octane $\left(\mathrm{C}_{8}\right)$, $\mathrm{n}$-dodecane $\left(\mathrm{C}_{12}\right)$ and $\mathrm{n}$-hexadecane $\left(\mathrm{C}_{16}\right)$ to examine the effects of chain length on mass distribution.

In Fig. 8, species are categorized based on organic moieties (isomers having identical functional groups are lumped together), and whether the species are produced by functionalization (with number of generation) or by decomposition routes. The letter code given in Fig. 9 for each category denotes the functional groups on the carbon backbones (N: nitrate, O: alcohol, K: ketone, D: aldehyde, E: ether, P: peroxyacetyl nitrate, S: ester, U: carbon double bond) or characteristics of the carbon backbone (T: cyclic structure, C: saturated aliphatic hydrocarbon - here the parent compound). A generic chemical mechanism leading to this set of species is presented in Fig. 9, with the codes corresponding to the various chemical structures.

For these experimental conditions, a large fraction of the parent hydrocarbon (denoted C in Fig. 8) persists after $1 \mathrm{~h}$ of oxidation (see Fig. 5). The simulated fraction of n-octane and $\mathrm{n}$-dodecane in the condensed phase is negligible. However, the partitioning of n-hexadecane to the particles and the walls is significant.

Major first generation products are alkylnitrates $(\mathrm{N}), 1,4-$ hydroxynitrates (NO), cyclic hemiacetals (denoted TOE and TOOE in Fig. 8) and dihydrofurans (denoted TUE in Fig. 8) produced from the fast cyclization of 1,4-hydroxyketones and 1,7-dihydroxy-4-ketones in the condensed phases assumed in this model configuration. Reaction sequences leading to the first generation products are repeated at other positions on the carbon backbones, leading to many second generation products (see Fig. 9). For example, alkyl nitrates react with $\mathrm{OH}$ producing dinitrate species $(\mathrm{NN})$, hydroxyketonitrates (NKO) and their corresponding cyclized form (TNOE). Oxidation of the hydroxyl moiety is significant as well. For example, the yields of the second generation ketonitrate (NK) are essentially explained by the oxidation of the first generation hydroxynitrate (NO). Figure S3 in the Supplement displays the fraction of DHF reacting with $\mathrm{OH}$ radical, $\mathrm{NO}_{3}$ rad$\mathrm{ical}$ and $\mathrm{O}_{3}$ by addition to the $\mathrm{C}=\mathrm{C}$ double bond, during the course of a typical alkane simulation. As expected, DHF oxidation is mainly driven by $\mathrm{OH}$ and leads to one of the major products, the carbonylesters (DS). However, DHF oxidation by $\mathrm{O}_{3}$ and $\mathrm{NO}_{3}$ appears to be also substantial (see Fig. S3) and explains the formation of acid carboxylic esters (AS) and cyclic dinitrate ethers (TNNE). Interestingly, the GECKO-A mechanisms lead to the production of lactones (TS) for short chain alkanes. These species are suspected to form oligomers (Kjaergaard et al., 2012). The model suggests that these lactones are produced in the gas phase from the $\mathrm{OH}$ radical oxidation of the cyclic hemiacetal structures via the abstraction of the hydrogen atom in the beta position relative to the hydroxyl group, ultimately leading to a specific alkoxy radical that forms the lactone by decomposition.

Figure 8 shows that wall uptake affects particular categories of species, depending on the chain length of the parent compound. As already discussed in the introduction, the partitioning of a species in the various phases is driven by its volatility. Similar chemical reactions are involved in the oxidation of long-chain alkanes, leading to the same families of species but with decreasing volatility when the size of the carbon skeleton increases. The vapor pressures of the major chemical families simulated during the alkane experiments are given as a function of the number of carbon atoms $\left(n_{\mathrm{C}}\right)$ in the backbone in Fig. 10. The shaded grey area corresponds to the volatility domain where significant partitioning to the walls is expected after $1 \mathrm{~h}$ (i.e., $10^{-8}-10^{-5} \mathrm{~atm}$; see Introduction).

The location of a given family in this volatility/nC framework largely explains the wall effect highlighted in Fig. 8. For example, for the alkyl nitrate family $(\mathrm{N})$, a first generation product, (i) $\mathrm{C}_{8}$ species appear to be too volatile to partition to the condensed particle phase (those are located on the right side of the grey area), (ii) $\mathrm{C}_{12}$ species are volatile enough to partition to the wall but not enough to substantially partition to the particles (even if no wall is considered) 


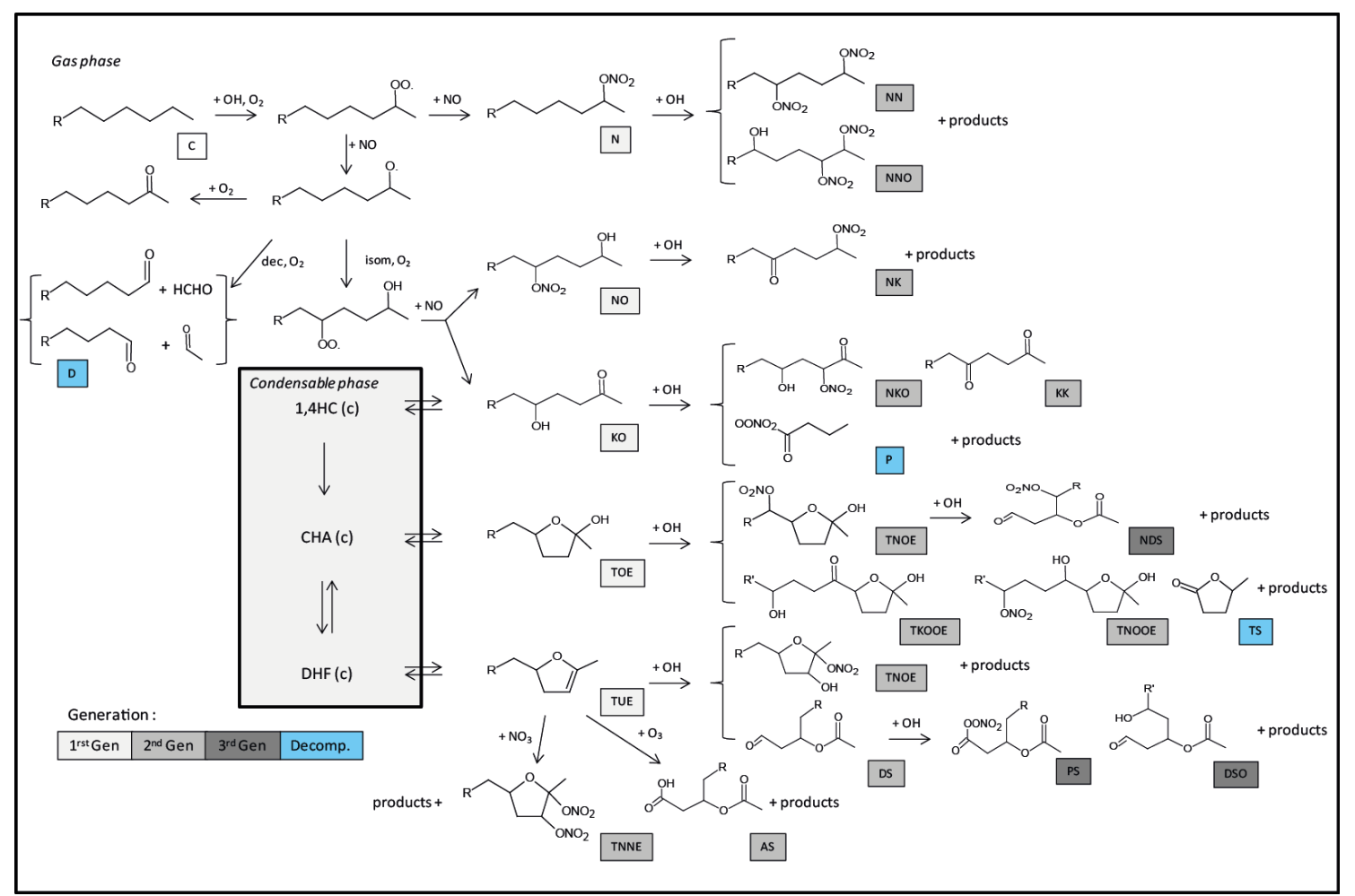

Figure 9. Generic GECKO-A chemical mechanism leading to the major products formed during n-alkane gaseous oxidation under high-NO $x$ conditions.

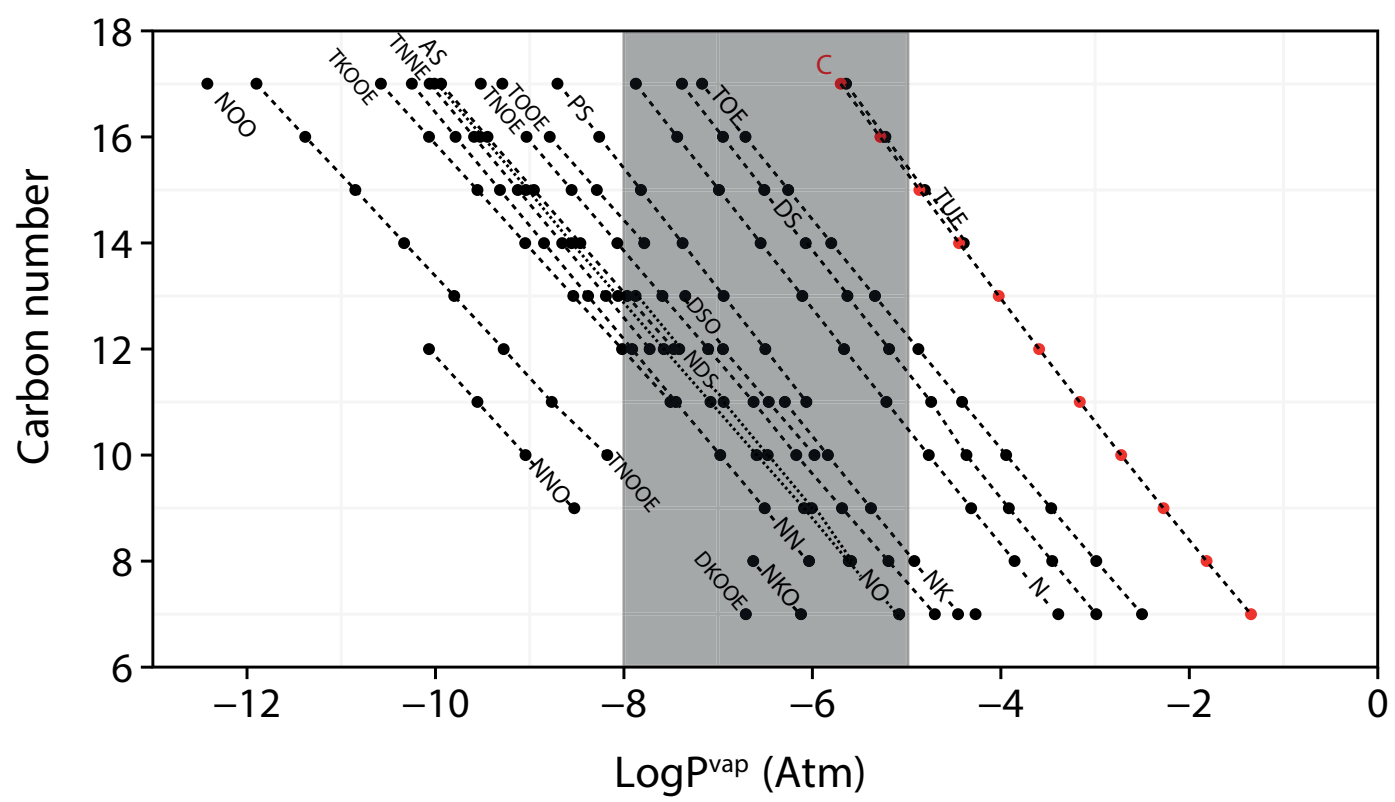

Figure 10. Saturation vapor pressure of the major products from functionalization routes simulated during n-alkane gaseous oxidation under high-NO $\mathrm{N}_{x}$ conditions as a function of the number of carbon atoms in the backbone. Dashed segments link two species with increasing carbon numbers within a chemical family to facilitate the reading of the figure. The grey zone represents the volatility range likely affected by gas-wall partitioning for a $1 \mathrm{~h}$ experiment (see text). 
Table 2. Decomposition and isomerization branching ratios for selected generic $\beta$-hydroxyalkoxy radicals produced from the oxidation of terminal, internal and 2-methyl alkenes as estimated by the ATK and VER configurations of the model and experimentally derived values by Matsunaga et al. (2009), Aschmann et al. (2010) and Ziemann (2011).

\begin{tabular}{lccc}
\cline { 3 - 4 } & \multicolumn{3}{c}{ Decomposition/isomerization branching ratio } \\
\cline { 3 - 5 } 1-alkenes configuration & VER configuration & Experimental data* \\
\hline
\end{tabular}

* Reported in Ziemann (2011).

and (iii) $\mathrm{C}_{16}$ species are mostly found in the condensed phase but the volatility is not low enough to prevent a substantial partitioning to the wall (those are still on the volatility domain where the walls substantially impact the species distributions). The mass reductions due to gas-wall partitioning for $\mathrm{C}_{8}, \mathrm{C}_{12}$ and $\mathrm{C}_{16}$ alkyl nitrates are, respectively, $-2,-40$ and $-7 \%$ in the gas phase, and -63 and $-26 \%$ in the particle phase for $\mathrm{C}_{12}$ and $\mathrm{C}_{16}$ species, respectively. Compared to the nitrate family, the volatility of the NO, also first generation products, is shifted toward lower volatility (typically by a factor of 30). For that $\mathrm{NO}$ family, $\mathrm{C}_{8}$ species partition to the walls to more than $50 \%$ (but not into the particles) affecting gas composition while $\mathrm{C}_{16}$ species are almost exclusively found in the particle phase, owing to their low volatility and the resulting kinetic control of the partitioning (see introduction). For $\mathrm{C}_{12}$ hydroxynitrates, $50 \%$ of the mass is lost into the walls modifying both gas and particle concentrations. The behavior of the first generation of cyclic hemiacetals (TOE) is similar to the nitrate family but most second generation species behave rather like the hydroxynitrate family, e.g., the dinitrates (NN) or the DHF oxidation products (TNOE, DS). The deposition of vapor to the walls during the experiments therefore splits a specific family of compounds and substantially alters both the simulated SOA yields and compositions.

\section{Conclusion}

In this study, simulations performed with the GECKO-A chemical mechanisms were assessed against 41 smog chamber experiments aimed at examining SOA formation during the $\mathrm{OH}$ oxidation of alkanes and alkenes under high $\mathrm{NO}_{x}$ conditions. Various homologous series of species were examined containing hydrocarbons with 7 to 17 carbon atoms. The set of parent hydrocarbons includes linear, cyclic and $\mathrm{C}_{12}$-branched alkanes and terminal, internal and 2-methyl alkenes. Wall loss of organic vapors was parameterized in the GECKO-A modeling tool to investigate the sensitivity of SOA formation to gas-wall partitioning.

Simulated trends match the experimental trends observed within and between homologous series. In particular, (i) SOA yield increases with the carbon skeleton size of the parent hydrocarbon, (ii) SOA yield increases from branched to linear to cyclic chemical structures, (iii) SOA yield decreases with the number of branches in the carbon backbone and (iv) SOA yield decreases from internal to terminal alkene isomers. The loss of organic vapors to the chamber wall is found to affect final SOA yields, with reductions ranging from a factor of 1.1 to 2 . The extent of this process depends on the rate of gaswall mass transfer and the vapor pressure of the species. As a result, the simulations of the alkene series (lasting $6 \mathrm{~min}$ ) appear insensitive to wall uptake, unlike the simulations for alkane series (lasting $1 \mathrm{~h}$ ).

Accounting for wall losses in the simulations of the alkane series improves significantly the agreement of the model re- 
sults with the observations, the overall best agreement being obtained when a fast gas to wall mass transfer rate is assumed. The composition of the gas and the particle phases is also impacted by wall losses. For the alkane series, both phases are mostly composed of first generation species produced along functionalization routes such as alkyl nitrates, 1,4-hydroxynitrates, cyclic hemiacetals and dihydrofurans coming from the fast cyclization of 1,4-hydroxycarbonyls in the particle. Second generation species are also found to be substantial contributors to SOA. These species are produced from $\mathrm{OH}$ oxidation and lead to additional functional groups (mostly nitrate, alcohol or carbonyl) on the carbon backbone. The presence of acid carboxylic esters (AS) and cyclic dinitrate ethers (TNNE) among the major simulated products suggests that DHF oxidation by $\mathrm{O}_{3}$ and $\mathrm{NO}_{3}$ can compete with $\mathrm{OH}$ oxidation during these experiments. Simulated distributions of the species in the various phases suggest that substantial amounts of nitrates, hydroxynitrates and carbonylesters could be lost onto the walls.

For the alkene series, the simulated SOA yields exhibit a strong dependence on the structure activity relationship used to estimate the fate of the alkoxy radicals. The gas-wall partitioning process cannot fully explain the discrepancies between the model and the observations. Some chemical pathways are clearly missing in the GECKO-A mechanism, e.g., dimers formation and/or heterogeneous oxidation in the particle phase. Thus, further investigations of SOA composition are required.

This work suggests that SOA yields inferred from chamber experiments could be substantially underestimated due to the loss of organic vapors to the wall of the chamber. This process also likely alters the inferred SOA composition. The gas-wall partitioning of organic compounds needs to be routinely characterized for smog chamber data and derived SOA yields. These characterizations appear to be a critical issue to support the development of SOA parameterizations for air quality and climate models based on experimental observations in atmospheric chambers.

\section{The Supplement related to this article is available online at doi:10.5194/acp-16-1417-2016-supplement.}

Acknowledgements. This research work has been supported by the French National Research Agency (ANR) within the ONCEM (ANR-12-BS06-0017) and MAGNIFY (ANR-14-CE010010) projects and the French National institute for Geophysical Research (CNRS-INSU) within the LEFE-CHAT program through the Dodec-AOS project.

PJZ acknowledges support from the National Science Foundation (NSF) under grants AGS-1219508 and AGS-1420007.

The National Center for Atmospheric Research is sponsored by the National Science Foundation. JLT and SM were partly supported by a US Department of Energy grant BER/DE-SC0006780.

Edited by: N. L. Ng

\section{References}

Aschmann, S. M., Arey, J., and Atkinson, R.: Kinetics and Products of the Reaction of OH Radicals with 3-Methoxy-3-methyl1-butanol., Environ. Sci. Technol., 45, 6896-6901, 2011.

Atkinson, R.: Rate constants for the atmospheric reactions of alkoxy radicals: An updated estimation method, Atmos. Environ., 41, 8468-8485, doi:10.1016/j.atmosenv.2007.07.002, 2007.

Atkinson, R. and Arey, J.: Atmospheric degradation of volatile organic compounds, Chem. Rev., 103, 4605-4638, doi:10.1021/cr0206420, 2003.

Atkinson, R., Arey, J., and Aschmann, S. M.: Atmospheric chemistry of alkanes: Review and recent developments, Atmos. Environ., 42, 5859-5871, doi:10.1016/j.atmosenv.2007.08.040, 2008.

Aumont, B., Szopa, S., and Madronich, S.: Modelling the evolution of organic carbon during its gas-phase tropospheric oxidation: development of an explicit model based on a self generating approach, Atmos. Chem. Phys., 5, 2497-2517, doi:10.5194/acp-52497-2005, 2005.

Aumont, B., Valorso, R., Mouchel-Vallon, C., Camredon, M., LeeTaylor, J., and Madronich, S.: Modeling SOA formation from the oxidation of intermediate volatility n-alkanes, Atmos. Chem. Phys., 12, 7577-7589, doi:10.5194/acp-12-7577-2012, 2012.

Aumont, B., Camredon, M., Mouchel-Vallon, C., La, S., Ouzebidour, F., Valorso, R., Lee-Taylor, J., and Madronich, S.: Modeling the influence of alkane molecular structure on secondary organic aerosol formation, Faraday Discuss., 165, 105-122, doi:10.1039/c3fd00029j, 2013.

Bowman, F. M., Odum, J. R., and Seinfeld, J. H.: Mathematical Model for Gas-Particle Partitionin G of Secondary Organic Aerosols, Atmos. Environ., 31, 3921-3931, 1997.

Camredon, M., Aumont, B., Lee-Taylor, J., and Madronich, S. The SOA/VOC/NO $\mathrm{NO}_{\mathrm{x}}$ system: an explicit model of secondary organic aerosol formation, Atmos. Chem. Phys., 7, 5599-5610, doi:10.5194/acp-7-5599-2007, 2007.

Camredon, M., Hamilton, J. F., Alam, M. S., Wyche, K. P., Carr, T., White, I. R., Monks, P. S., Rickard, A. R., and Bloss, W. J.: Distribution of gaseous and particulate organic composition during dark a-pinene ozonolysis, Atmos. Chem. Phys., 10, 2893-2917, doi:10.5194/acp-10-2893-2010, 2010.

Cappa, C. D. and Wilson, K. R.: Multi-generation gas-phase oxidation, equilibrium partitioning, and the formation and evolution of secondary organic aerosol, Atmos. Chem. Phys., 12, 9505-9528, doi:10.5194/acp-12-9505-2012, 2012.

Cavalli, F., Barnes, I., and Becker, K. H.: FT-IR Kinetic and Product Study of the $\mathrm{OH}$ Radical-Initiated Oxidation of 1-Pentanol, Environ. Sci. Technol., 34, 4111-4116, doi:10.1021/es000016p, 2000.

Cocker, D. R., Flagan, R. C., and Seinfeld, J. H.: State-of-theart chamber facility for studying atmospheric aerosol chemistry, Environ. Sci. Technol., 35, 2594-2601, doi:10.1021/es0019169, 2001.

Donahue, N. M., Epstein, S. A., Pandis, S. N., and Robinson, A. L.: A two-dimensional volatility basis set: 1. organic-aerosol mixing thermodynamics, Atmos. Chem. Phys., 11, 3303-3318, doi:10.5194/acp-11-3303-2011, 2011.

Gong, H., Matsunaga, A., and Ziemann, P. J.: Products and mechanism of secondary organic aerosol formation from reactions of linear alkenes with $\mathrm{NO}_{3}$ radicals., J. Phys. Chem. A, 109, 4312 4324, doi:10.1021/jp0580241, 2005. 
Heicklen, J.: The decomposition of alkyl nitrites and the reactions of alkoxyl radicals, in: Advances in Photochemistry, Volume 14, edited by: Volman, D. H., Hammond, G. S., and Gollnick, K., John Wiley \& Sons, Inc., Hoboken, NJ, USA, 177-272, 1988.

Jenkin, M. E., Young, J. C., and Rickard, A. R.: The MCM v3.3.1 degradation scheme for isoprene, Atmos. Chem. Phys., 15, 11433-11459, doi:10.5194/acp-15-11433-2015, 2015.

Jimenez, J. L., Canagaratna, M. R., Donahue, N. M., Prevot, A. S. H., Zhang, Q., Kroll, J. H., DeCarlo, P. F., Allan, J. D., Coe, H., Ng, N. L., Aiken, A. C., Docherty, K. S., Ulbrich, I. M., Grieshop, A. P., Robinson, A. L., Duplissy, J., Smith, J. D., Wilson, K. R., Lanz, V. A., Hueglin, C., Sun, Y. L., Tian, J., Laaksonen, A., Raatikainen, T., Rautiainen, J., Vaattovaara, P., Ehn, M., Kulmala, M., Tomlinson, J. M., Collins, D. R., Cubison, M. J., Dunlea, E. J., Huffman, J. A., Onasch, T. B., Alfarra, M. R., Williams, P. I., Bower, K., Kondo, Y., Schneider, J., Drewnick, F., Borrmann, S., Weimer, S., Demerjian, K., Salcedo, D., Cottrell, L., Griffin, R., Takami, A., Miyoshi, T., Hatakeyama, S., Shimono, A., Sun, J. Y., Zhang, Y. M., Dzepina, K., Kimmel, J. R., Sueper, D., Jayne, J. T., Herndon, S. C., Trimborn, A. M., Williams, L. R., Wood, E. C., Middlebrook, A. M., Kolb, C. E., Baltensperger, U., and Worsnop, D. R.: Evolution of organic aerosols in the atmosphere., Science, 326, 1525-1529, doi:10.1126/science.1180353, 2009.

Kjaergaard, H. G., Knap, H. C., Ørnsø, K. B., Jørgensen, S., Crounse, J. D., Paulot, F., and Wennberg, P. O.: Atmospheric fate of methacrolein. 2. Formation of lactone and implications for organic aerosol production, J. Phys. Chem. A, 116, 5763-5768, doi:10.1021/jp210853h, 2012.

Kokkola, H., Yli-Pirilä, P., Vesterinen, M., Korhonen, H., Keskinen, H., Romakkaniemi, S., Hao, L., Kortelainen, A., Joutsensaari, J., Worsnop, D. R., Virtanen, A., and Lehtinen, K. E. J.: The role of low volatile organics on secondary organic aerosol formation, Atmos. Chem. Phys., 14, 1689-1700, doi:10.5194/acp-14-16892014, 2014.

Kroll, J. H. and Seinfeld, J. H.: Chemistry of secondary organic aerosol: Formation and evolution of low-volatility organics in the atmosphere, Atmos. Environ., 42, 3593-3624, doi:10.1016/j.atmosenv.2008.01.003, 2008.

Kwok, E. S. C. and Atkinson, R.: Estimation of hydroxyl radical reaction rate constants for gas-phase organic compounds using a structure-reactivity relationship: An update, Atmos. Environ., 29, 1685-1695, doi:10.1016/1352-2310(95)00069-B, 1995.

Lee-Taylor, J., Hodzic, A., Madronich, S., Aumont, B., Camredon, M., and Valorso, R.: Multiday production of condensing organic aerosol mass in urban and forest outflow, Atmos. Chem. Phys., 15, 595-615, doi:10.5194/acp-15-595-2015, 2015.

Lim, Y. B. and Ziemann, P. J.: Products and mechanism of secondary organic aerosol formation from reactions of n-alkanes with $\mathrm{OH}$ radicals in the presence of $\mathrm{NO}_{x}$, Environ. Sci. Tech., 39, 9229-9236, doi:10.1021/es051447g, 2005.

Lim, Y. B. and Ziemann, P. J.: Chemistry of Secondary Organic Aerosol Formation from $\mathrm{OH}$ Radical-Initiated Reactions of Linear, Branched, and Cyclic Alkanes in the Presence of $\mathrm{NO}_{x}$, Aerosol Sci. Tech., 43, 604-619, doi:10.1080/02786820902802567, 2009a.

Lim, Y. B. and Ziemann, P. J.: Effects of molecular structure on aerosol yields from $\mathrm{OH}$ radical-initiated reactions of linear, branched, and cyclic alkanes in the presence of $\mathrm{NO}_{x}$, Environ. Sci. Technol., 43, 2328-2334, doi:10.1021/es803389s, 2009b.

Lim, Y. B. and Ziemann, P. J.: Kinetics of the heterogeneous conversion of 1,4-hydroxycarbonyls to cyclic hemiacetals and dihydrofurans on organic aerosol particles, Phys. Chem. Chem. Phys., 11, 8029-8039, doi:10.1039/b904333k, 2009c.

Loza, C. L., Chan, A. W. H., Galloway, M. M., Keutsch, F. N., Flagan, R. C., and Seinfeld, J. H.: Characterization of vapor wall loss in laboratory chambers, Environ. Sci. Technol., 44, 5074-5078, doi:10.1021/es100727v, 2010.

Martin, P., Tuazon, E. C., Aschmann, S. M., Arey, J., and Atkinson, R.: Formation and atmospheric reactions of 4,5dihydro-2-methylfuran, J. Phys. Chem. A, 106, 11492-11501, doi:10.1021/jp021499h, 2002.

Matsunaga, A.: Secondary organic aerosol formation from radicalinitiated reactions of alkenes: development of mechanisms, $\mathrm{PhD}$ Dissertation thesis, University of California, Riverside, CA, 2009.

Matsunaga, A. and Ziemann, P. J.: Gas-Wall Partitioning of Organic Compounds in a Teflon Film Chamber and Potential Effects on Reaction Product and Aerosol Yield Measurements, Aerosol Sci. Tech., 44, 881-892, doi:10.1080/02786826.2010.501044, 2010.

Matsunaga, A., Docherty, K. S., Lim, Y. B., and Ziemann, P. J.: Atmospheric Environment, J. Phys. Chem., 43, 1349-1357, doi:10.1016/j.atmosenv.2008.12.004, 2009.

McMurry, P. H. and Grosjean, D.: Gas and Aerosol Wall Losses in Teflon Film Smog Chambers, Environ. Sci. Technol., 19, 11761182, doi:10.1021/es00142a006, 1985.

Nannoolal, Y., Rarey, J., Ramjugernath, D., and Cordes, W.: Estimation of pure component properties: Part 1. Estimation of the normal boiling point of non-electrolyte organic compounds via group contributions and group interactions, Fluid Phase Equilibr., 226, 45-63, doi:10.1016/j.fluid.2004.09.001, 2004.

Nannoolal, Y., Rarey, J., and Ramjugernath, D.: Estimation of pure component properties part 3. Estimation of the vapor pressure of non-electrolyte organic compounds via group contribution and group interactions, Fluid Phase Equilibr., 269, 117-133, doi:10.1016/j.fluid.2008.04.020, 2008.

Pankow, J. F.: An absorption model of the gas/aerosol partitioning involved in the formation of secondary organic aerosol, Atmos. Environ., 28, 189-193, doi:10.1016/1352-2310(94)900949, 1994.

Pathak, R. K., Stanier, C. O., Donahue, N. M., and Pandis, S. N.: Ozonolysis of $\alpha$-pinene at atmospherically relevant concentrations: Temperature dependence of aerosol mass fractions (yields), J. Geophys. Res.-Atmos., 112, 1-8, doi:10.1029/2006JD007436, 2007.

Presto, A. A. and Donahue, N. M.: Investigation of alphapinene + ozone secondary organic aerosol formation at low total aerosol mass, Environ. Sci. Technol., 40, 3536-3543, doi:10.1021/es052203z, 2006.

Santiago, M., Vivanco, M. G., and Stein, A. F.: Evaluation of CMAQ parameterizations for SOA formation from the photooxidation of $\alpha$-pinene and limonene against smog chamber data, Atmos. Environ., 56, 236-245, doi:10.1016/j.atmosenv.2012.04.011, 2012.

Seinfeld, J. H. and Pandis, S. N.: Atmospheric chemistry and physics: from air pollution to climate change, 2nd Edn., Wiley, Hoboken, NJ, 2006. 
Shiraiwa, M. and Seinfeld, J. H.: Equilibration timescale of atmospheric secondary organic aerosol partitioning, Geophys. Res. Lett., 39, 1-6, doi:10.1029/2012GL054008, 2012.

Taylor, W. D., Allston, T. D., Mascato, M. J., Fazekas, G. B., Kozlowski, R., and Takacs G. A.: Atmospheric photodissociation lifetimes for nitromethane, methyl nitrite and methyl nitrate, Int. J. Chem. Kinet., 12, 231-240, 1980.

Valorso, R., Aumont, B., Camredon, M., Raventos-Duran, T., Mouchel-Vallon, C., Ng, N. L., Seinfeld, J. H., Lee-Taylor, J., and Madronich, S.: Explicit modelling of SOA formation from apinene photooxidation: sensitivity to vapour pressure estimation, Atmos. Chem. Phys., 11, 6895-6910, doi:10.5194/acp-11-68952011, 2011.

Vereecken, L. and Peeters, J.: Decomposition of substituted alkoxy radicals-part I: a generalized structure-activity relationship for reaction barrier heights., Phys. Chem. Chem. Phys., 11, 90629074, doi:10.1039/b909712k, 2009.

Vereecken, L. and Peeters, J.: A structure-activity relationship for the rate coefficient of H-migration in substituted alkoxy radicals, Phys. Chem. Chem. Phys., 12, 12608-12620, doi:10.1039/c0cp00387e, 2010.

Verwer, J. G. and van Loon, M.: An evaluation of explicit pseudosteady-state approximation schemes for stiff ODE systems from chemical kinetics, J. Comput. Phys., 113, 347-352, 1994.

Verwer, J. G., Blom, J. G., van Loon, M., and Spee, E. J.: A comparison of stiff ODE solvers for atmospheric chemistry problems, Atmos. Environ., 30, 49-58, doi:10.1016/1352-2310(95)002835, 1996.

Yeh, G. K. and Ziemann, P. J.: Alkyl nitrate formation from the reactions of $\mathrm{C}_{8}-\mathrm{C}_{14} n$-alkanes with $\mathrm{OH}$ radicals in the presence of $\mathrm{NO}_{x}$ : measured yields with essential corrections for gas-wall partitioning., J. Phys. Chem. A, 118, 8147-8157, doi:10.1021/jp500631v, 2014.
Yeh, G. K. and Ziemann, P. J.: Gas-Wall Partitioning of Oxygenated Organic Compounds: Measurements, StructureActivity Relationships, and Correlation with Gas Chromatographic Retention Factor, Aerosol Sci. Tech., 49, 727-738, doi:10.1080/02786826.2015.1068427, 2015.

Zhang, X. and Seinfeld, J. H.: A functional group oxidation model (FGOM) for SOA formation and aging, Atmos. Chem. Phys., 13, 5907-5926, doi:10.5194/acp-13-5907-2013, 2013.

Zhang, X., Cappa, C. D., Jathar, S. H., McVay, R. C., Ensberg, J. J., Kleeman, M. J., and Seinfeld, J. H.: Influence of vapor wall loss in laboratory chambers on yields of secondary organic aerosol, P. Natl. Acad. Sci. USA, 111, 5802-5807, doi:10.1073/pnas.1404727111, 2014a.

Zhang, X., Schwantes, R. H., Coggon, M. M., Loza, C. L., Schilling, K. A., Flagan, R. C., and Seinfeld, J. H.: Role of ozone in SOA formation from alkane photooxidation, Atmos. Chem. Phys., 14, 1733-1753, doi:10.5194/acp-14-1733-2014, 2014b.

Zhang, X., Schwantes, R. H., McVay, R. C., Lignell, H., Coggon, M. M., Flagan, R. C., and Seinfeld, J. H.: Vapor wall deposition in Teflon chambers, Atmos. Chem. Phys., 15, 4197-4214, doi:10.5194/acp-15-4197-2015, 2015.

Ziemann, P. J.: Effects of molecular structure on the chemistry of aerosol formation from the OH-radical-initiated oxidation of alkanes and alkenes, Int. Rev. Phys. Chem., 30, 161-195, doi:10.1080/0144235X.2010.550728, 2011. 